\title{
COVID-19: o mensageiro da nova morte
}

\author{
https://doi.org/10.21814/uminho.ed.23.5
}

\section{Albertino Gonçalves}

\begin{abstract}
Albertino Gonçalves (ORCID: 0000-0002-5673-0497) é Professor Associado do Departamento de Sociologia da Universidade do Minho e investigador do Centro de Estudos Comunicação e Sociedade (CECS), ambos da Universidade do Minho. Especializado nas áreas da sociologia da cultura e da arte, reparte a sua atividade entre a vida académica e a intervenção na comunidade. Publicou, como autor, os livros Imagens e Clivagens: os residentes face aos emigrantes (1996), As Asas do Diploma: A Inserção Profissional dos Licenciados pela Universidade do Minho (2001) e Vertigens: Para uma Sociologia da Perversidade (2009).
\end{abstract}




\section{NEM A MORTE NOS REÚNE ${ }^{1}$}

Uma epidemia global, abrupta, sem termo. O vírus não se vê, não se ouve, nem se toca, mas apodera-se de nós. Contamina a um ritmo letal de que a vida não tem memória. Apóstolos da ciência, o desconhecimento desarma-nos. A vacina e a cura encobrem-se num nevoeiro sebastiânico. O poder está em estado de alerta e a sociedade em estado de alarme. De um momento para outro, sentimo-nos indefesos. O confinamento cristaliza esta vulnerabilidade. A adesão foi franca. Face ao perigo, encolhemo-nos e recolhemo-nos como caracóis.

A pandemia, que mobiliza organizações e instituições nacionais e internacionais, configura uma calamidade pública que exige intervenção coletiva. Tudo é enorme, monstruoso, à medida de um olhar macrossociológico. Mas importa estar atento à pulsação das minudências quotidianas, senão privadas. Importa cultivar um olhar míope, microssociológico. Ver de perto o confinamento do mundo da vida, incluindo a interação, os rituais e as relações pessoais.

Não é de menosprezar a ideia, entretanto vulgarizada, de um afrouxamento dos laços sociais. O reverso aponta, com a crise, para um estreitamento dos laços à escala doméstica. Se as ruas estão desertas, as casas estão atestadas. Pior do que a compressão no espaço, é a extensão no tempo. O espaço partilha-se, mais ou menos, como dantes, mas de forma permanente e sem termo certo, o que configura uma experiência inédita. A gente acomoda-se e incomoda-se. Cada membro da família negoceia os seus recantos. A cada um, o seu nicho de intimidade e restauro da identidade. Sucedem-se refúgios individuais e encruzilhadas comuns. Dia após dia, afina-se a sensibilidade à intrusão. É tempo de stress. Desconheço os efeitos deste convívio forçado prolongado. Tanto pode reforçar a coesão e a harmonia, como pode degenerar em conflito e descompensação. Duvido que Zygmunt Bauman (2006) tenha previsto o presente cenário. Um afrouxamento dos laços sociais sistemático e do tamanho do planeta.

\footnotetext{
1 O presente texto é composto por duas partes distintas. A primeira, "nem a morte nos reúne”, foi publicada, durante o confinamento, na página Communitas, do Centro de Estudos Comunicação e Sociedade (http:// www.communitas.pt/ideia/nem-a-morte-nos-reune/). Finaliza com duas perguntas a que a segunda parte, "morte infeciosa", escrita em tempo de desconfinamento, procura responder.
} 
Uma deriva das famílias numa espécie de esmigalhamento global. Convém moderar esta leitura. Diminuída ou não, a sociedade sobrevive. Em alguns sectores, de um modo intenso e com elevada carga emocional. Se uns abrandam, outros aceleram. Por ofício ou por solidariedade. Acresce que a sociedade não se reduz a matéria, nem o ator social, a um boneco articulado. $\mathrm{O}$ essencial da dinâmica social é intangível. Até numa situação de isolamento físico é possível cuidar das ligaçôes e dos laços. As novas tecnologias permitiram-nos ganhar a aposta do intercâmbio à distância.

Nesta pandemia, a relação com o espaço assevera-se crucial. Há quem nunca saia de casa e há quem não o pode evitar. Expõe-se a uma experiência única em termos de proxémica (Hall, 1986). O espaço pessoal, a esfera da intimidade (Simmel, 1981) ou bolha de honra (Durkheim, 1924), comprime-se em casa e avoluma-se no supermercado, na padaria, na farmácia ou no posto de abastecimento. "Pelo menos, dois metros entre as pessoas”. Uma nova antropologia. O corpo parece um fole: acanha-se em casa e avoluma-se na rua. Um efeito Alice. Mais estranha do que a proxémica, é a relação com as pessoas: somos todos poluídos e poluidores potenciais. E afastamo-nos. Os olhares não se cruzam, esquivam-se, para vergonha humana.

Ocupa-se o espaço como se proporciona. Segmento a segmento. E o tempo, como o suportamos? As refeiçóes nunca foram tão esmeradas, a limpeza tão infinita, os livros tão folheados. Enfrenta-se o tempo com a ajuda das novas tecnologias, a fada-madrinha da nossa vida borralheira. Televisores, computadores, telemóveis, consolas, videojogos, capacetes de realidade virtual e redes sociais animam o tédio e enganam o vazio. No Brasil, a internet registrou, no dia 23 de março, um fluxo de tráfego de 11 $\mathrm{Tb} / \mathrm{s}$, contra 4,69 Tb/s ao longo de $2019^{2}$. Até as visualizações do blogue 'Tendências do Imaginário’ cresceram 77,9\%.

O ecrã é um parceiro. Configura, com o usuário, uma extensão recíproca. Imaterial? Os sentidos andam baralhados (Kerckhove, 1997). O material e o imaterial, também. Até os olhos conseguem tatear (figura 1). Horas e dias a interagir com a máquina. Imersão?

2 https://www.nexojornal.com.br/expresso/2020/03/29/Como-a-pandemia-afeta-a-infraestrutura-da-internet. 
Transubstanciação e expansão. Os novos media franqueiam portas e janelas. Estendem pontes. São uma chave mestra. Graças ao telemóvel ou à Internet, as pessoas comunicam tanto ou mais do que antes. "Juntas à distância”!

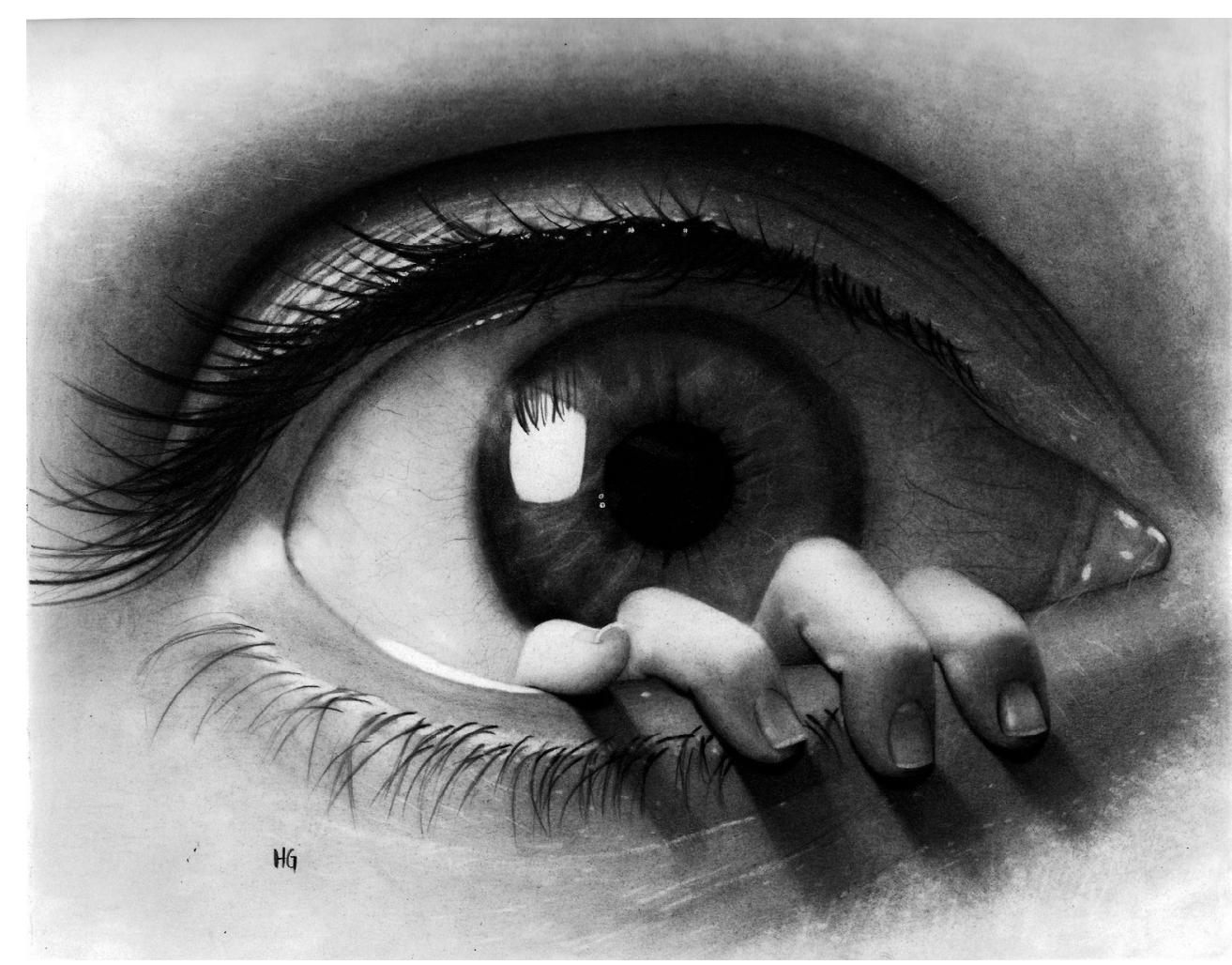

Figura 1. Hector Gonzalez. 2015.

A publicidade proclama o "milagre” das novas tecnologias. Nos anúncios, o ecrã surge como uma fatalidade, uma companhia incontornável. É um interlocutor, um parceiro de jogo ou de comunicação, sempre disponível para interagir. Os novos media, mais do que transformar a realidade numa ilusão, transformam a ilusão numa realidade, sensível (Baudrillard, 1991). "Dão novos mundos ao mundo”. É neste ambiente que o corpo "comanda” o ecrã e o ecrã se faz corpo. A grande evasão dos confinados.

O anúncio With Love, Jack!, da marca de whiskey Jack Daniel's (Estados-Unidos, 26 de março de 2020), faculta uma ilustração da química do homem eletrónico 3 . Atarda-se numa sequência de atividades que superam distâncias e barreiras: namora-se;

3 https://www.nexojornal.com.br/expresso/2020/03/29/Como-a-pandemia-afeta-a-infraestrutura-da-internet. 
conversa-se; disputa-se um jogo de xadrez com o adversário no telemóvel; partilha-se a refeição; promovem-se reuniões; simulam-se amigos; trocam-se palmadas; copiam-se gestos; brinda-se e festeja-se. Sem recurso às novas tecnologias, improvisa-se um ténis de mesa na cozinha e transforma-se o vidro do prédio num tabuleiro de jogo do galo (figura 2). Tudo acompanhado por uma garrafa ou um copo de whiskey.

$\mathrm{Na}$ parte final, surge a frase: "Dear Humanity / Cheers to making social distancing / social. / With love, / Jack”.

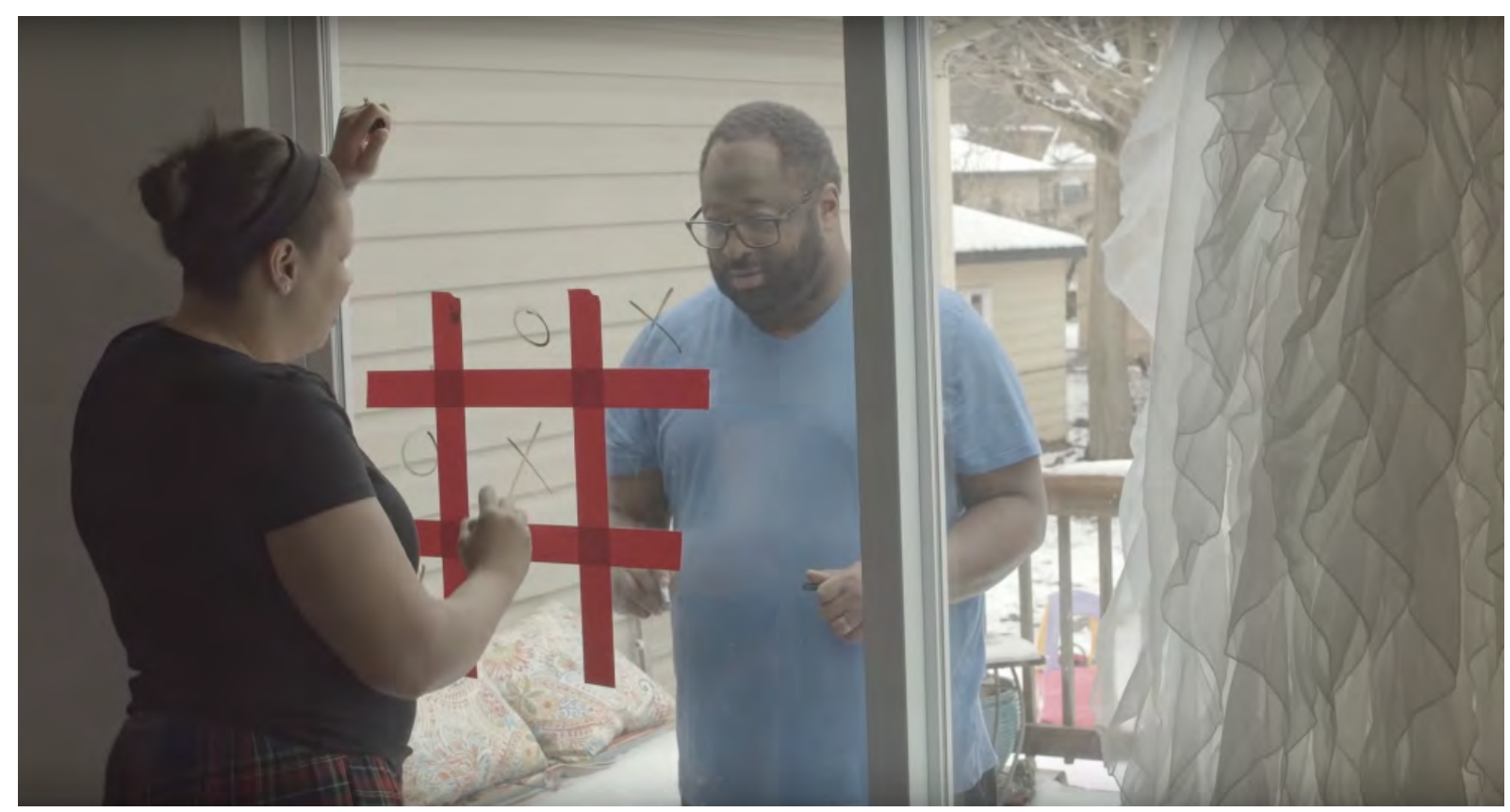

Figura 2. Jack Daniel's. With love, Jack! Energy BBDO. Estados-Unidos, março 2020.

Se a comunicação eletrónica reveste foros de salvação, a despedida dos mortos, sem exéquias, afasta-nos do purgatório.

““Só a morte nos reúne” podia ser refrão de uma dança macabra medieval. Mas não! É atual. Só a morte nos reúne quando a vida nos separa. Com ou sem compressão do espaço e do tempo. Com ou sem comunicação multimédia. Com ou sem próteses. Com ou sem liquidez. Com ou sem hiper-realidade. Com ou sem tribos. $\mathrm{O}$ mundo da vida, o mundo de cada um, não se encolheu, aumentou. E nós perdemo-nos nesse mundo! Neste tempo de laços, afetos, sentimentos e 
emoções, “só a morte nos reúne” é um aforismo do misto de desencontro e urgência que preside ao nosso modo de estar na vida" ${ }^{\prime 4}$.

Os mortos passam para o outro mundo, trespassam, sem velório, sem missa e sem funeral. Palpita-me que os mortos não sentirão a falta. Mas para os vivos é fundamental. Há séculos que assim acontece. E se assim acontece há séculos, talvez haja motivo e tenha bom efeito. Uma má despedida é um mau porto de partida. Sem fases e sem rituais, é um abalo da alma para a família, para os amigos e para a comunidade. É uma ferida sensível, identitária, simbólica e afetiva. É um mau recomeço para o futuro. O funeral é, porventura, o principal acontecimento ritual de uma comunidade. Mais que o batismo, o casamento ou qualquer outra cerimónia. Tăo grave como a abreviação da despedida é a entorse no luto, uma fase de reparação que convoca os outros significativos. Só, ou quase, na despedida; só, ou quase, no luto. Entre os problemas decorrentes da pandemia, dois carecem especial cuidado. Como vão sair as famílias do confinamento? Como vão as famílias resolver as despedidas e os lutos amputados, atípicos? Em 2018, ocorreram em Portugal 113051 óbitos. Uma média de 310 por dia (fonte: INE). Hoje, devido ao coronavírus, são mais.

\section{A MORTE INFECIOSA}

Seis semanas após o início da terceira fase do "plano de desconfinamento" (1 de junho de 2020) chega, porventura, o momento de retomar algumas questóes sobre a experiência do confinamento e do desconfinamento.

A mobilização do sistema de saúde foi ímpar. A política de controlo das consequências económicas e sociais foi consensual. Sectores como a educação eas autarquias corresponderam. A intervenção e a monitorização apostaram na racionalização, na técnica e na ciência. Mobilizaram-se recursos, minimizaram-se prejuízos e conteve-se o vírus. O dispositivo de comunicação, consubstanciado no balanço diário com a presença da Ministra da Saúde e da Diretora-Geral da Saúde, foi

4 https://tendimag.com/2015/12/07/so-a-morte-nos-reune/. 
abrangente, consistente e, sobretudo, notório. Números, normas, leituras e conselhos. Um ritual de equipa (Goffman, 1956). "O medo é um vírus e a informação é a vacina”.

O desconfinamento depende do confinamento, cuja vertente cognitiva e psicológica justifica alguma apreensão. A divulgação da sintomatologia, muito probabilista, desencadeou uma vaga de "doentes imaginários". Os balanços diários de informação estatística orientam, mas também distorcem: a "massagem" (McLuhan, 2018) dos números pode fazer-se acompanhar de um efeito de abstração (Sorokin, 1956; Mills, 1959). A normalização e a comparação colidem com a diversidade e a substância. A (in)formação sobre a doença, nomeadamente na sua dimensão experiencial, foi relativamente discreta. O retrato do novo coronavírus desenhou-se atendendo, sobretudo, aos sintomas e aos números. Configura um "monstro vazio" (Calabrese, 1999). Parcialmente vazio, mas igualmente perturbador. Não é por acaso que a humanidade se apressa a dar corpo e rosto ao mal. Fabricou, por exemplo, uma infinidade de imagens do Diabo. O monstro vazio é um ser que está "em toda a parte e em parte nenhuma" (Pascal, 1998). A geografia do mal, o "sentido dos limites" e a noção de risco asseveram-se problemáticos. Para quem esteve, meses a fio, refém do presente e órfão de futuro, este desnorte pode contribuir para o excesso e o desvio. $\mathrm{O}$ anúncio do desconfinamento foi recebido com alívio e um leve toque de euforia.

Com o desconfinamento, o rosto do monstro adquire outra face. As notícias sobre a doença e a morte por coronavírus, de discretas, passam a ostensivas. Dois excertos, dos jornais Público e Expresso, ilustram o foco na doença e o risco de desorientação.

"O homem terá contraído a doença numa "festa COVID", um evento social que junta pessoas na companhia de alguém infetado, desafiando a sorte (...) Antes de o doente morrer, olhou para a sua enfermeira e disse: 'Acho que cometi um erro. Pensava que isto era uma fraude, mas não é”.

“Bruno Lopes não estranhou as dores de cabeça que julgava serem provocadas

\footnotetext{
5 Jorge Almeida Fernandes, Público 29 de fevereiro de 2020, 6:56; https://www.publico.pt/2020/02/29/ mundo/opiniao/medo-virus-informacao-vacina-1905931.

6https://expresso.pt/coronavirus/2020-07-13-Enganei-me-diz-antes-de-morrer-um-doente-de-30-anos-quenao-acreditava-na-COVID-19.
} 
pela troca de turnos, nem a febre repentina a meio da noite. Mas, quando acordou, a tosse compulsiva fê-lo ligar para o SNS 24, que o encaminhou para o hospital de Santo Tirso. Três hospitais e quase um mês e meio depois, o segurança de 36 anos voltou a casa. Um testemunho na primeira pessoa de alguém que recuperou da COVID-19, mas nunca esperou "que a doença fosse tão forte como foi" .

Após a pandemia, a morte jamais será a mesma. Trata-se de um salto sem retorno. Transcrevo alguns excertos das orientações do Ministério da Saúde relativas aos "Cuidados após o falecimento de pessoas com infeção suspeita ou confirmada por SARS-CoV-2”:

“- Tamponar todos os orifícios naturais do cadáver, para evitar extravasamento de fluidos corporais (...)

- Acondicionar o corpo embrulhando-o no lençol absorvente que faz parte integrante do saco de cadáver, colocá-lo no saco impermeável, apropriado e encerrar adequadamente $(. .$.

- De preferência, cremar os cadáveres, embora não seja obrigatório fazê-lo;

- O cadáver deve sempre permanecer no saco impermeável (preferencialmente dupla embalagem) e em caixão fechado (...)

- Não abrir o caixão (...)

- Não permitir eventos que impliquem, ou possam implicar, a concentração de mais de 20 pessoas"

(Orientações cadáveres, Ministério da Saúde, março 2020).

Salvaguardadas as proporções, no que respeita ao cuidado com os cadáveres, a pandemia COVID-19 situa-se nas antípodas da Peste Negra, período em que os cadáveres

7https://www.publico.pt/2020/07/14/p3/depoimento/sai-casa-hospital-nao-vi-ninguem-testemunho-bruno-36-anos-20-dias-cuidados-intensivos-1924261?utm_term=Bruno+esteve+internado $+u m+$ mes $+e+-$ $\underline{\text { meio+com+COVID-19. }}$. 
se amontoavam nas ruas e nas casas (ver figura 3). Tamponar os orifícios naturais, trânsito da vida (Bakhtin, 1987), embrulhar o corpo em duas embalagens de plástico e transportá-lo em caixão fechado representa um zelo tecnicamente justificável. Tragicamente, não dispomos de outra solução, senão isolar e desinfetar. Não obstante, este zelo cinzela a nossa identidade. A cultura dos povos revela-se na sua relação com os mortos (Thomas, 1988). A múmia expressa o Egipto Antigo; o transi, a Idade Média; a fotografia post mortem, a era vitoriana; o holocausto, o século XX; e o embrulho em duplo saco plástico, o início do terceiro milénio. Há fenómenos aparentemente acessórios que se apoderam, simbolicamente, da imagem global. Recordo a farda dos médicos durante a peste negra (ver figura 4).

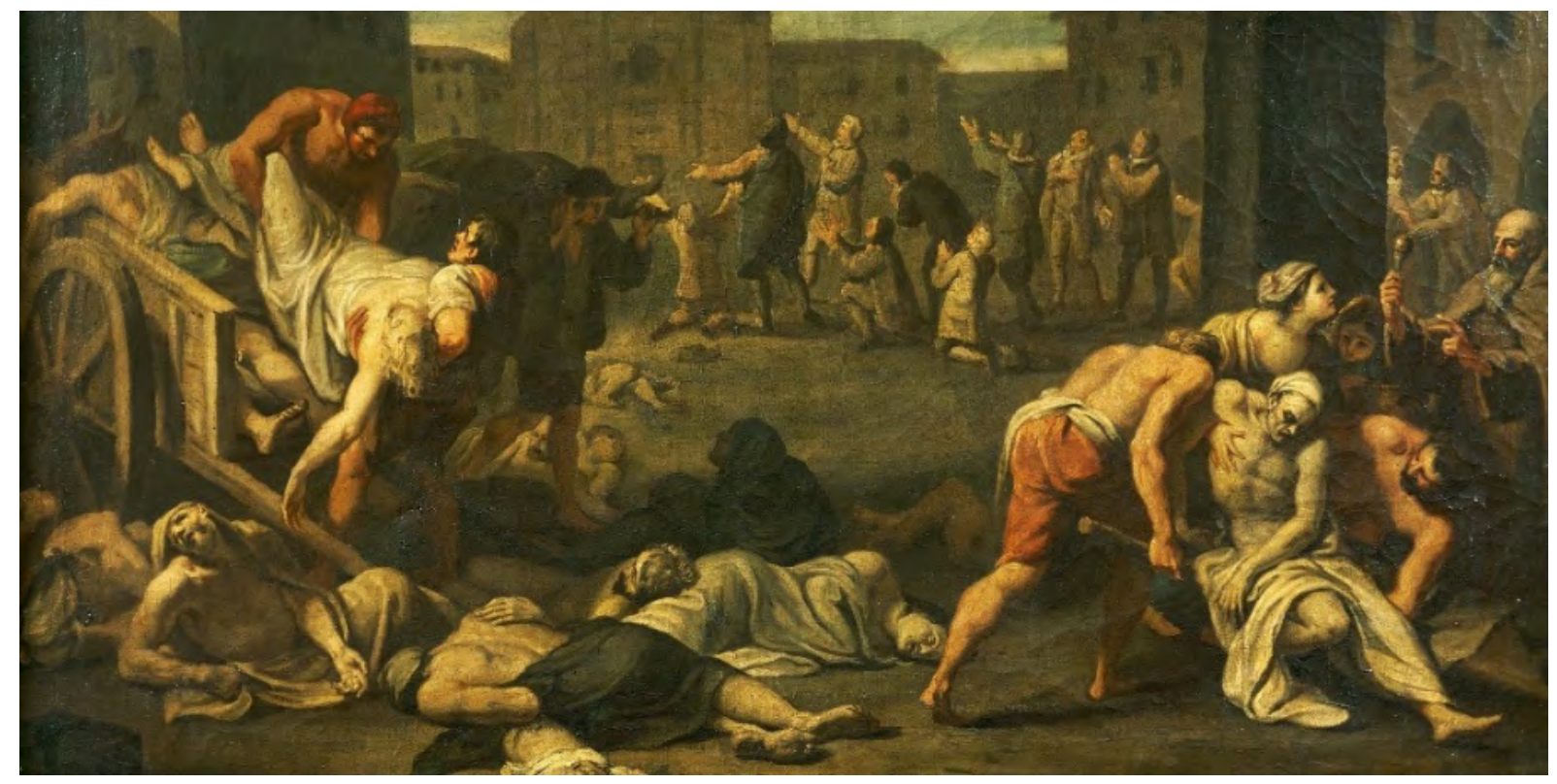

Figura 3. Ilustração da peste em Itália, no século XVII. Museo Storico Nazionale Dell’Arte Sanitaria. 


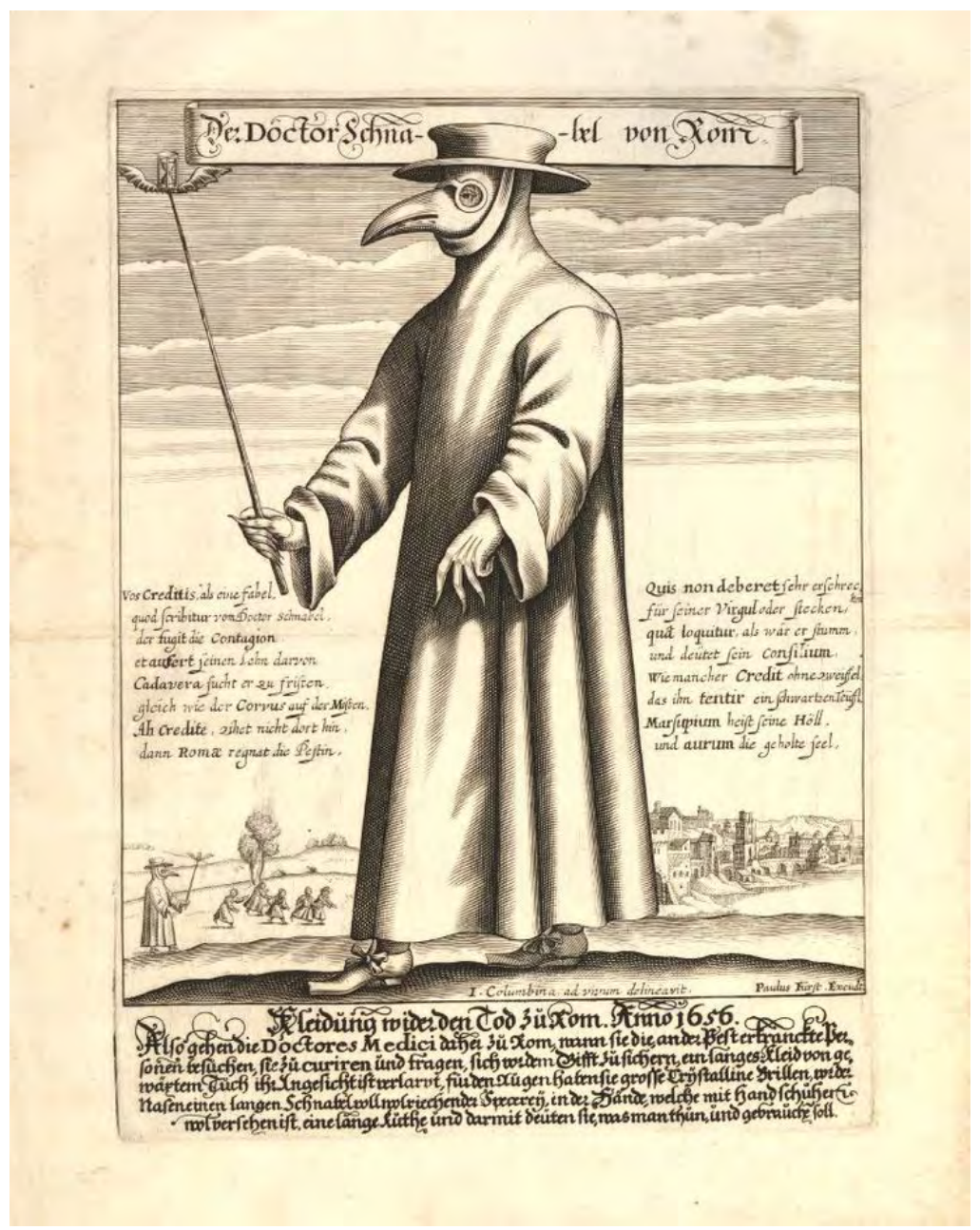

Figura 4. Paulus Furst. Gravura do Dr. Schnabel de Roma. Equipamento de médico durante a peste negra. 1656.

Ao isolamento dos cadáveres, somou-se a interdição de visitas a hospitais e lares de idosos. Uma conjugação fértil em situações estranhas. As pessoas “despedem-se”, quando têm oportunidade, de familiares e amigos ainda vivos, dias ou semanas antes do óbito. Caso contrário, nem vivo, nem morto. Ninguém adivinha. Abre-se um novo mundo. A vida encolhe-se numa morte social (Thomas, 1979). Apaga-se sem familiares, sem amigos, sem sentido e sem dor. A ausência de despedida e os "cuidados com o cadáver" não se reduzem a meros procedimentos objetivos; são falhas no mundo da vida, são enxertos anómalos no imaginário. É a potência da fragilidade. 


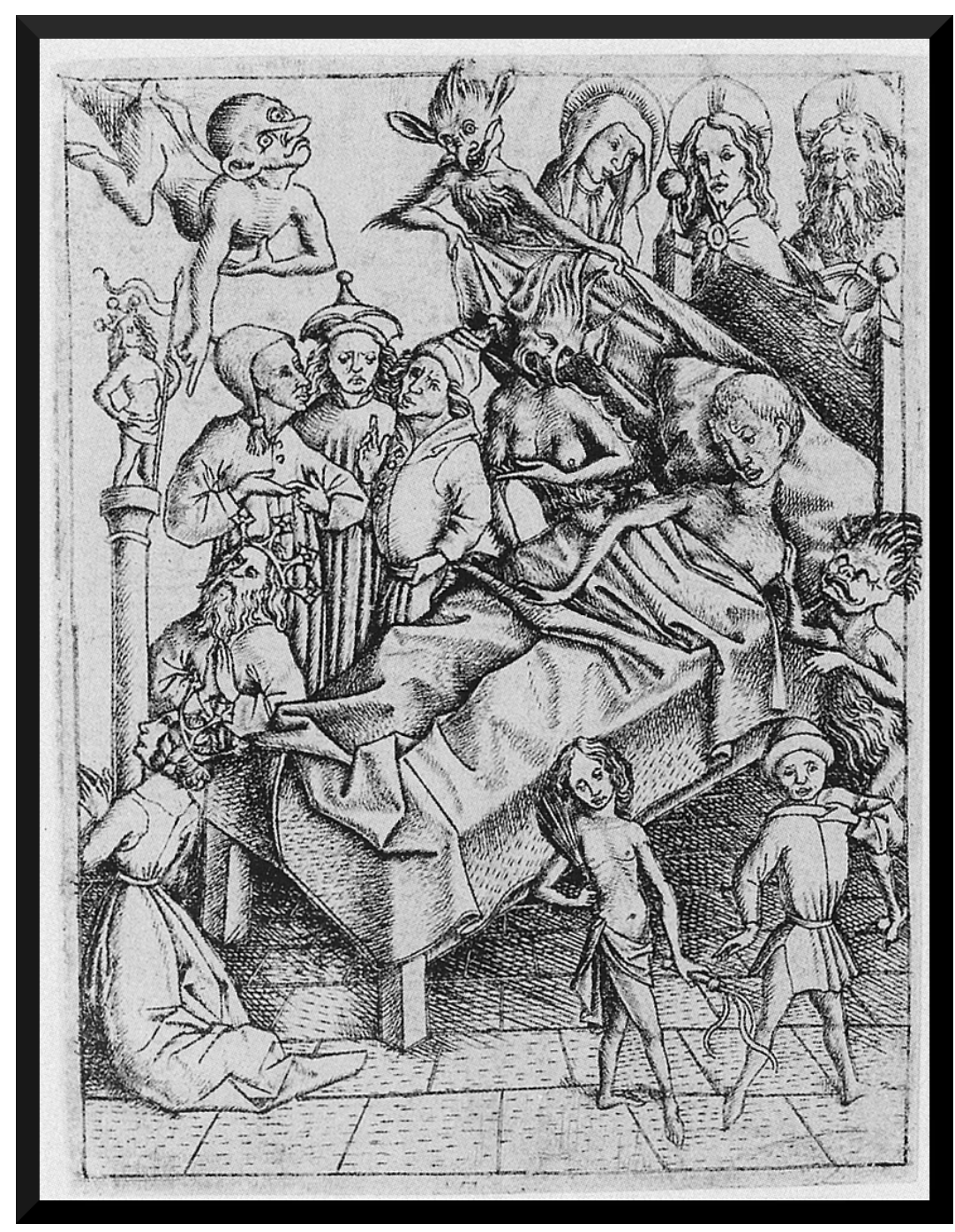

Figura 5. Mestre E. S. Ars moriendi, Tentação da Fé, c. 1450.

Historicamente, o último suspiro era o mais importante, o culminar da vida. Assim o estipulavam os livros, medievais e modernos, dedicados à ars moriendi. Receava-se morrer em combate ou por acidente, porque se comprometia a passagem (Ariès, 1977). O ideal era morrer no leito, rodeado pela família, pelos amigos e pelos anjos e demónios, que disputavam, na derradeira prova, a alma do defunto (ver figura 5). Hoje, a partida, a travessia, é cada vez mais solitária e cada vez mais expedita (Elias, 2002). Como se o rio de Caronte tivesse perdido as margens. 


\section{REFERÊNCIAS}

Ariès, Ph. (1977. Essai sur l'histoire de la mort en Occident. Paris: Points.

Bakhtin, M. (1987). Cultura Popular na Idade Média e no Renascimento: o contexto de François Rabelais. São Paulo: Hucitec.

Baudrillard, J. (1991). Simulacro e simulação. Lisboa: Relógio d’Água.

Bauman, Z. (2006). Amor Líquido: Sobre a Fragilidade dos Laços Humanos. Lisboa: Relógio d’Água.

Calabrese, O. (1999). A Idade Neobarroca. Lisboa, Edições 70.

Durkheim, É. (1924). Sociologie et philosophie. Paris: Alcan.

Elias, N. (2002). La solitude des mourant. Paris: Poche.

Goffman, E. (1956). The presentation of self in everyday life. Nova Iorque: Double Day.

Hall, E. T. (1986). A Dimensão Oculta. Lisboa: Relógio d’Água.

Kerckhove, D. (1997). A Pele da Cultura. Lisboa: Relógio d’Água.

McLuhan, M. (2018). O meio é a massagem. São Paulo: Ubu Editora.

Mills, C. W. (1959). The Sociological Imagination. Oxford University Press.

Pascal, B. (1998). Pensamentos. Lisboa: Publicações Europa-América.

Simmel, G. (1981). Sociologie et épistémologie. Paris : P.U.F.

Sorokin, P. A. (1956). Fads and Foibles in Modern Sociology. Chicago: H. Regnery Co.

Thomas, L-V. (1988), Anthropologie de la Mort. Paris: Payot.

Thomas, L-V. (1979), Civilisation et divagations. Mort, fantasmes, science-fiction. Paris: Payot. 